\title{
Concept map of dispositional humility among professionals in an interdisciplinary healthcare environment: qualitative synthesis
}

This article was published in the following Dove Press journal: Journal of Multidisciplinary Healthcare

\section{Masa Sasagawa \\ Paul S Amieux}

Bastyr University Research Institute, Bastyr University, Kenmore, 98028, USA

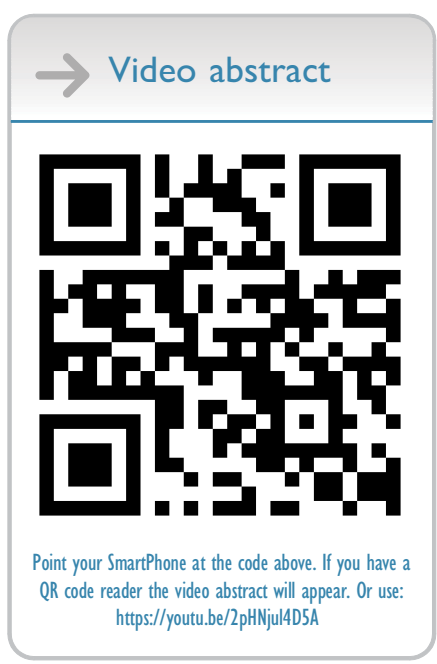

Correspondence: Masa Sasagawa

Bastyr University, I 14500 Juanita Dr., NE, Kenmore, WA 98028, USA

Email msasagawa@bastyr.edu
Background: US healthcare consumers increasingly demand more integrative medical care. Collaboration among clinicians trained in different professional disciplines and specialties may require particular character traits and/or training that focus on factors that facilitate effective collaborative work. Dispositional humility may be a factor that balances selffocused desire for recognition with other-focused professional collaboration to serve patients. The objective of this paper is to create a concept map of dispositional humility in healthcare professionals as a factor to enhance collaboration.

Methods: Articles published between 1997 and 2017 were searched using the term "dispositional humility" or titles containing "humility" AND either "leadership," "cultural," "religious," "relational," or "personality." The abstracts were screened for relevance and full articles were located. To strengthen the scientific rigor of qualitative work by systematizing a method of concept analysis, the Walker and Avant's eight-step concept analysis was used.

Results: Ninety-five articles were reviewed in the qualitative synthesis, including 82 fulltext articles from the original search and 13 full-text articles containing the concepts "empathy," "professionalism" or "openness" identified from references found in the 82 articles. A concept map was created after interpreting the contents of these articles.

Conclusions: Collaboration requires not only professional competency but also positive dispositional factors. Dispositional humility allows clinicians to have an accurate self-assessment, to be open to new ideas, to appreciate the contribution of others, and to develop generosity. Dispositional humility in leaders can facilitate character development of team members and create an environment characterized by fairness and equality, transparency, non-punitive consequences for reporting errors and near-misses, and a safe and encouraging environment. Nonetheless, dispositional humility must be nurtured and developed through professional training because high educational attainment, career and financial success, and busy schedules may lead to a sense of self-importance and entitlement that promotes separation of team members into hierarchies based on professional disciplines and specialties.

Keywords: dispositional humility, interprofessional relations, interdisciplinary communication, health care economics and organizations

\section{Introduction}

To understand a concept, underlying historical and other social context should be explained to clarify the significance of "dispositional humility." A concept map is an educational tool to visualize relationships between ideas surrounding a particular concept. In order to explore a culture of collaboration in interdisciplinary settings 
with workers in the healthcare professions, psychosocial definitions of humility require contextual exploration. Educational psychologists suggest that humans possess an instinctive tendency toward irrationality but also a native capacity for rationality. ${ }^{1}$ While our irrational mind is not concerned with the rights and needs of others, our rational mind seeks to monitor our own tendency toward egocentric or irrational thinking and modifies such thinking with corrective rational thought. ${ }^{1}$ To collaborate we must show concern for the rights and needs of others. If our natural tendency works against these requirements for collaboration, then we need to maximize our capacity toward rationality. The word collaboration derives from the Latin "collaborare" and is found referenced in the French literature of $1860 .^{2}$ Collaboration connotes not only working together, but is also used for "traitorous cooperation with an enemy," implying working together with a party of opposing interest.

In the healthcare setting, an opposing interest may be associated with a different discipline or specialization. The concept of specialization or discipline was developed from classical Greek philosophy, the product of Plato's account of the principle of specialization and its extension to the design of the state and its educational institutions. ${ }^{3}$ In order to create a flourishing society, the principle of specialization entered the Republic (state) with the arrival of the first city: The City of Pigs. "The creator of this first city is our need for food, housing, clothing, shoes, and so on. Isolated individuals are unable to provide for these needs and so band together to remedy their lack." (p. $139)^{3}$ Before the time of industrialization, one's aptitude to a particular specialization or craft became evident by demonstrating facile comportment of one's mind, body and character to the acquisition of a specific task; hence, the specialization of tasks due to the nature/attributes of the individual developed into occupations. It is not difficult to speculate that this was a teleology of the division of labor to increase productive efficiency discussed in the Wealth of Nations. ${ }^{4}$

Socioeconomic and political influence drove some occupations to achieve superior hierarchical status compared to others in modern society. Parsons (1939) analyzed the creation of social structures seen through the lens of motivational factors of people in different occupations and observed that "professionals," as groups associated with specific occupations, tend to be motivated by altruism and service to society, while "business people" are motivated by more self-serving behaviors, such as the pursuit of personal profit. ${ }^{5}$ Furthermore, an individual's interest in making a large income was not only the desire for purchasing power but also a symbol of their own perception of self-worth and value to society. Motivation for pursuing success in either business or the professions may imply the individual's motivation is related to egoism or altruism. ${ }^{5}$ If egoism and self-interest dominate among professionals, the instinctively irrational mind may dominate, and instead of monitoring our own irrationality, we may use rational thinking to justify the creation of an egocentric and selfserving social structure that includes self-serving political ties, formation of academic cliques, administrative connections and the promotion of a hierarchy of professions and a separation of disciplines that safeguards the social, economic and political interests of one profession over another. However, in the case of clinicians as professionals, the overarching philosophy remains altruism rather than egoism. ${ }^{6}$ While claiming productive efficiency and improved care as the rationale for dividing healthcare systems into disciplines and specializations, we may be hiding this bottom line of what Parsons calls: "enlightened self-interest."

Humility may be a dispositional factor that describes a different aspect of mental maturity in the individual that makes the person aware of the irrational mind and may help them utilize rational thinking in a more auspicious way. Neither the tendencies of the mind nor the personality disposition has been a focus of scientific investigation for model development on collaboration in the healthcare work environment, perhaps because we assume that education and rigorous professional training will modify our irrational instinct. For example, trained professionalism by means of education was defined by the American Board of Internal Medicine's commissioned Project Professionalism as: altruism, accountability, excellence, duty, honor/integrity, and respect. ${ }^{7}$ If educational training alone can help someone attain the professionalism described above, then there is no need to worry about the irrational and egoistic instinctive tendency of the mind in professional interactions. The investigation of whether professional education alone is sufficient to maintain collaborative work is not the aim of this paper. The aim is to construct a concept map of dispositional humility. This paper is also part of an overarching research question about whether or not dispositional humility is an important factor in an interprofessional collaborative environment. An awareness of and a focus on dispositional humility may instill a culture that facilitates a more favorable interprofessional collaborative environment in educational and professional institutions. 


\section{Methods}

This qualitative synthesis of a concept map used a hybrid method by combining a systematic literature search with interpretive analysis of recurring themes. A literature search was performed using Medline, EMBASE, CINAHL, and PsychINFO database for articles published from 1997 to 2017. To be selected for qualitative synthesis, the contents of an article had to show relevance to humility. A synthesis was then performed based on Walker and Avant's eight-step concept analysis: 1) select a concept by narrowing down the social and contextual specifications and expressed by a word or shortest terms, 2) determine the aims or purpose of analysis to clarify an objective for scientific reasons, 3) identify all uses of the concept that can be discovered by diversifying the key element, 4) determine defining attributes of the different use discovered from step number 3,5 ) identify a model as exemplars of the concept of interest, 6) identify comparative cases as opposing exemplars and borderline examples, 7) identify consequences and antecedents as associated phenomena of the concept, and 8) finally define the term using principles and information demonstrated (empirical cases) in previous steps. ${ }^{8}$ The processes of the systematic search and the eight-step qualitative synthesis are described further in the section below.

\section{Analyses Systematic search}

Figure 1 shows the literature selection process. The search term "dispositional humility" returned only 12 articles from the databases. Duplicate articles were removed from the sum of the 12 articles plus articles searched by title containing "humility" AND either "leadership", "cultural", "religious", "relational", or "personality." Out of 302 articles, 155 were removed after reading the abstract because the contents did not focus on the discussion of humility. Out of 147 possible articles, 82 full text articles were located. While reading these articles, 13 additional articles that were not included in the database search were identified. These additional articles demonstrated a relation to concepts such as "empathy", "professionalism" and "openness." A total of 95 articles were used for the qualitative synthesis.

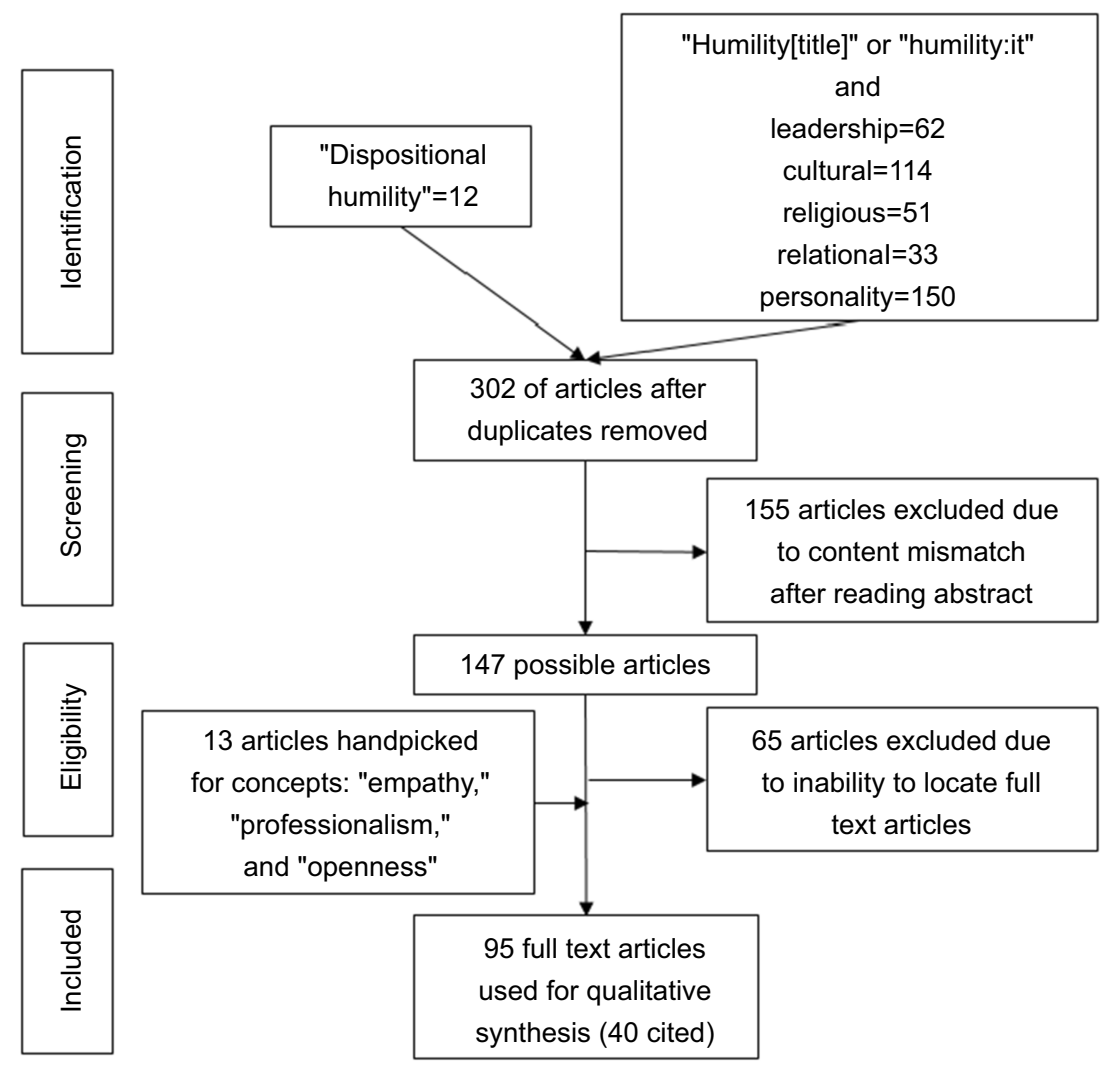

Figure I Articles published in 1997-2017. The flow chart based on the PRISMA guideline ${ }^{53}$ indicates the initial database selection that excluded dissertations and books and included reviews and letters to the editor. When similar or duplicated themes were identified, earlier publications were selected. Articles with topics of empathy and openness emerged while reviewing humility articles. Articles on professionalism were also handpicked in order to create the concept map (Figure 2 ). 


\section{Eight-step qualitative synthesis Concept to be analyzed}

The concept under discussion is "dispositional humility" in healthcare professionals with diverse training backgrounds, credentialing, and healthcare philosophies. The "disposition" refers to an enlightened nature or character traits that are genuinely expressed as opposed to cognitively controlled behaviors or calculated interpersonal skills. The word "humility" is used in many psychosocial contexts. In the professional setting, dispositional humility is not displayed as meekness or a lack of self-esteem. A description of the psychological construct may include non-judgmental openmindedness to respect different points of view while maintaining the virtue of a positive psychological character. ${ }^{9}$ Dispositional humility is negatively associated with arrogance-related concepts such as egotistical, high-and-mighty, closed-minded, and conceited. ${ }^{10}$

Aims and purposes of defining dispositional humility An aim is to create a concept map and to conceptualize how "dispositional humility" plays a role in integrative primary healthcare environments including ethical or professional training. A concept map allows health professional educators and administrators to modify curricula or training programs to enhance collaborative working relationships.

\section{Identifying the terms used in different contexts}

The concepts of humility discussed are: leadership humility, religious humility, cultural humility, intellectual humility, organizational humility, relational humility and the personality factor presenting humility.

\section{Leadership humility}

Leadership humility is a term found in the science of workforce management and administration. ${ }^{11,12}$ In democratic leadership styles such as "shared leadership", the team members' input is maximized ${ }^{13}$ and creativity enhanced ${ }^{14}$ because of the flexibility of the leader in accepting opinions of other team members. In the context of leadership, narcissism often comes up because we often choose leaders with this personality attribute. ${ }^{15}$ Individuals displaying "hubris" or individuals with excessive pride and self-confidence often wish to become leaders to claim self-importance and control. ${ }^{16}$ However, humility referred to in the context of leadership literature is often defined as a negative attribute because leaders cannot be humble and are required to be charismatic to instill confidence in the working group. ${ }^{11,13}$ Charisma is often associated with extravert characteristics, with strong convictions that are attractive to others. In the professional environment, leadership humility is characterized by being open to admitting one's limitations and mistakes, and showing appreciation as well as giving credit to others. ${ }^{14}$ Leadership training may require teaching humility because insufficient self-awareness with power may have devastating consequences for a team. "An inability to display introspection and self-examination may lead to overestimation of one's own capabilities, especially if one is in a position of power." (p. 98) ${ }^{17}$

\section{Religious humility}

Religious scriptures often teach humility as a central virtue. When research participants were primed by reading stories depicting humility before being criticized as part of an experiment, religious people tended to maintain less retaliatory intentions toward criticism when compared to non-religious people. ${ }^{18}$ This study showed that religious people might pick up the cue to become humble (self-aware and open to criticism) more than their non-religious counterparts. ${ }^{18}$ Another study hypothesized that humility is enhanced in older individuals (age $>66$ years old) by interaction with likeminded others in the religious community (in this case Christian) because people jointly construct their social view of the world. ${ }^{19}$ Krause (2010) defined humility as obedience to God and God's teaching, and "pride" was considered the antonym of humility. This conclusion is concerning to a society with people of diverse beliefs because of the phenomena known as "in-group favoritism". ${ }^{20,21}$ People with the same beliefs have the same social identification and this makes it easier for them to cooperate ${ }^{20}$ while people who are not identified as the same group may find it difficult to cooperate or may be actively excluded. Krause's definition of humility may appear detrimental to enhancing interdisciplinary collaboration; however, other researchers explain (spiritual) humility differently. Fostering greater humility is considered a part of character development for juvenile offenders, and the act of helping others flows from a spiritually grounded humility. ${ }^{22}$ Lee et al (2017) viewed the treatment of addictive behaviors through the spiritual virtues of humility and altruism. Humility and teachability are characterized by having an accurate sense of one's self and abilities, along with an openness to accepting input from others. ${ }^{22}$ If such humility is extended outside a group identified as self, interprofessional interaction will be benefitted. 


\section{Cultural humility}

"Cultural humility" describes an environment or attitude that accepts and respects diverse cultural beliefs and practices. ${ }^{23-26}$ "Cultural humility" was defined as a lifelong process of self-reflection and self-critique, to redress the power imbalances in interpersonal dynamics, and to developing mutually beneficial and mutual advocacy partnerships. ${ }^{26}$ Cultural humility demonstrates

a willingness and openness to reflect on one's own self as an embedded cultural being, having an awareness of personal limitations in understanding the cultural background and viewpoint of others. (p. 661) ${ }^{27}$

Alsharif (2012) urges healthcare training curricula to assure the acquisition of cultural humility as one of the educational competencies. ${ }^{28}$ However, he does not define cultural humility as acquirable like skills. In regards to creating an environment that facilitates cultural humility,

some leadership teams are exceptionally humble, which theoretically enhances transparency, engages fairness and equality, facilitates reporting of errors and near misses, and sustains a safe environment for staff members to excel. (p. 28) ${ }^{29}$

Similar concepts found in the published literature include intellectual humility and organizational culture characterized by humility (organizational humility). Intellectual humility emphasizes the awareness of our own intellectual limitations despite high achievement, and displays an ability to accept different points of view. ${ }^{30-32}$ Organizational humility explains the combination of cultural humility and leadership humility with the principle of servant leadership. ${ }^{29}$

\section{Relational humility}

Relational humility implies humble characteristics displayed or perceived by others in any relationship. Interpersonal modesty refers to "the tendency to moderate praise or recognition in socially acceptable ways." (p. $225)^{33}$ The Relational Humility Scale ${ }^{33}$ was developed to assess the presence of human virtue that was rooted in religion to foster belief and obedience to God. ${ }^{19}$ However, some authors mentioned that the self-reporting form of the humility scale may not quantify the true nature of a person because "the truly humble person has a natural tendency to underestimate the presence of virtue, and acclaim of the presence would be immodest." (p. 2) ${ }^{34}$ Three attributes commonly discussed about humility in relationships are: 1) accurate assessment of self, 2) modest social portrayal, and 3) other-oriented rather than self-focused. ${ }^{35}$ These attributes are believed to reduce dyadic stress $^{35}$ and enhance commitment in romantic relationships. ${ }^{36}$

When people see their partners acting selfishly and arrogantly, they view their partners as less humble, which leads them to see the relationship as a riskier investment, which causes lower commitment and relationship satisfaction. (p. 16)

Clearly, the perceived humility resulting from the actions and mannerism of others will enhance the chance of success in a relationship. So what types of actions and mannerisms are culturally perceived as humble? As an example, "time spent" is a critical and limited commodity for working professionals. If a professional demands work from another professional without respecting the other's time, this interaction may be perceived as "not humble" or "non-collaborative" behavior.

\section{Humility as a personality factor}

Personality dispositions are features or qualities of a person's nature as opposed to trained skills. Paul and Elder (2002) define human minds as having an instinctive tendency toward irrationality and a native capacity for rationality, a dispositional factor (humility) may be described by both instinctive tendencies and rational thoughts. A caution is needed in describing this duality because we are also capable of legitimizing the irrational instincts of selfishness and egotism by using the rational mind by justifying the formation of, for example, professional membership, social or institutional hierarchy, and social, political or financial advantage. The western clinician's professionalism overlaps with the aforementioned definitions of various humility attributes. ${ }^{37}$ Whether or not rigorous professional training can modify personality dispositional factors is debatable. Trained skills may be perceived by others as fake or inauthentic. Humility was also found to be a robust predictor of generosity toward close friends, strangers, and even enemies. ${ }^{38}$ To quantitatively measure the level of general humility, the HEXACO personality questionnaire (with six domains of personality) was developed, ${ }^{39}$ which includes an Honesty/Humility (HH) factor as one of the personality domains. ${ }^{40}$ The HH domain is subdivided into four facets: sincerity, fairness, greed-avoidance, and modesty. ${ }^{41}$ The HH unfolds the subject's basic prosocial orientation and behaviors and the expectation that others are also prosocial and trustworthy. ${ }^{42}$ By combining the concept of honesty with humility, the $\mathrm{HH}$ domain quantifies the dispositional 
character of individuals toward developing trusting relationships.

\section{Determine the attributes of dispositional humility}

The recurring or common attributes observed in the previous section are also summarized in several publications: ${ }^{22,35,38,43}$ Accurate assessment of one's abilities and achievements; ability to acknowledge one's mistakes, imperfections, gaps in knowledge, and limitations; openness to new ideas, contradictory information and advice, teachability; keeping one's abilities and accomplishments in perspective; modest social portrayal of self as a part of the larger universe; appreciation of the value of all things, as well as the many different ways that people and things can contribute to our world; otheroriented rather than self-focused thinking; with respect to self-preservation in a competitive society (finances, pride, recognition), people with humility are more generous by giving accolades and benefits to others; lack of entitlement and willingness to work hard to earn by achievement. A study of social relationship quality reported a positive correlation between a revised Quality Marriage Index and the HEXACO humility score in college students. ${ }^{44}$

Humility counters selfish inclinations such as entitlement and narcissism, and is considered the opposite of arrogance-the belief that we are wiser or better than others. ${ }^{43}$ The following terms showed divergent validity for humility during the creation of the Dispositional Humility Scale: ${ }^{45}$ arrogant, egotistical, high-and-mighty, closed-minded, conceited, selfish, and entitlement.

Narcissism and pride were discussed as antagonistic concepts of humility with some attributes not necessarily antonymous. Certain attributes of narcissism such as self-absorption and lack of empathy toward others are antagonistic; however, humility of professionals should never include self-loathing or an inferiority complex. Some level of self-love and pride must be present. Unless professionals possess a pathological level of narcissism or overbearing pride, these attributes may co-exist with the concept of humility. In other words, some level of pride and self-esteem can strengthen the maintenance of humility; however, at the same time, those individuals may also be considered arrogant due to an overbearing humility.

\section{Identify a model case of dispositional humility}

The Chief of Vanderbilt's Division of Obstetric Anesthesiology, David Chestnut, described the decline of publications containing terms such as honesty, truthfulness, humility, modesty, honor and sacrifice ${ }^{37} \mathrm{He}$ reflected about his own professional success by describing how he learned humility in the context of his professional life. After his academic and professional training, he was bursting with overbearing confidence. One day his senior fellow conveyed to him the feelings expressed by the head nurse, where she talked about how much she hated working with him, and the senior fellow informed Dr. Chestnut that he must change or lose his position. Apparently, this prompted him to reflect on his arrogant attitudes and mannerisms. As he observed his own interaction with nurses, he realized how much nursing staff could teach him about the essentials of good teamwork. This case describes the duality of the human mind: Selfcentered irrationality and the corrective rational nature prompted by the prospect of professional failure (job loss). His natural reaction to become self-aware and admit his shortcomings demonstrated his dispositional humility. If he was not in fact a humble attending physician, he could have retaliated against the head nurse; however, he did not. "When I needed to make a clinical decision, I would often ask the nurses for advice. They taught me a lot." (p. 780) ${ }^{37} \mathrm{He}$ also noted that "Arrogance and pride are self-destructive. Ironically, a person who possesses true humility does not have the slightest idea that he or she is humble." (p. 781) ${ }^{37}$ This is an interesting characteristic of humility, despite the fact that it enhances self-awareness, and humble clinicians may not realize their own virtue. Chestnut went on to quote Duffy (2009), stating that in teaching professionalism, we should include the care of the doctor's soul, by practicing social displays of gratitude and humility and observing that healing miracles occur by working together as a team. ${ }^{46}$ The commitment to lifelong learning is a hallmark of medical professionalism. ${ }^{37}$ As Chestnut advanced in his professional career toward a greater leadership role, he explained the value of servant leadership and stated the importance of treating team members well by learning their names, treating them with respect, and by expressing gratitude for their work. $^{37}$

\section{Identify comparative cases}

According to Walker and Avant, comparative cases are exemplars of borderline cases and antagonistic cases. In this section, characteristics of people with operationally measured humility as part of the personality. Dispositional humility (in the general context not limited to professional relationships) is explored in personality psychology and operationalized by psychometric instruments including the HEXACO personality inventory. By combining humility and honesty, the HH domain in the HEXACO incorporates the propensity toward developing positive and trustworthy 
relationships in social interactions. To identify what is not dispositional humility, those who were characterized by having low $\mathrm{HH}$ scores presented behavioral characteristics in the workplace called "Impression Management Behaviors (IMB)". ${ }^{47}$ Five types of IMB were

1) ingratiation [doing favors and using flattery and opinion conformity to be seen as likeable by the target], 2) selfpromotion [playing up one's own accomplishments to be seen as competent by the target], 3) exemplification [going above and beyond what is expected to be seen as dedicated by the target], 4) intimidation [signaling power or the potential to punish in order to be seen as dangerous by the target], and 5) supplication [advertising one's weaknesses to be seen as needy by the target]. (p. 537) ${ }^{47}$

Individuals with low $\mathrm{HH}$ and associated IMB present characteristics of manipulation, deceit, and exploitation. Bourdage (2014) described the dispositional basis of IMB, and although coworkers may not accurately perceive it, it is confirmed by having low $\mathrm{HH}$ scores. Extraverts are sociable and if they are high in approval-seeking behaviors, they may place strong emphasis on gaining the acceptance of others by creating positive images of themselves. These portrayals of a positive self are not humility, even though it is directed at gaining acceptance and being liked by others. ${ }^{48}$

Some researchers raise a concern about the direction of humility research because humility has been defined mainly by academic researchers as a "virtue" and the layperson's input has not been incorporated. ${ }^{49}$ Weidman et al (2016) conducted five series of studies with a total of 1,479 participants that identified two kinds of humility: "appreciative humility" and "self-abasing humility". 49 Personal success elicits appreciative humility, which generates actions to appreciate others and is positively associated with psychological dimensions like pride, guilt, and prestige-based status. Self-abasing humility comes from personal failure and involves negative evaluation of self and actions to hide from others' evaluation; psychological states such as shame, low self-esteem, and submissiveness are associated with selfabasing humility. ${ }^{49}$ They called these definitions of humility the "darker side" ${ }^{49}$ However, this study was based on the "experimental induction of a momentary humility experience." A person who experiences embarrassment often is not the basis of dispositional humility, which is the dispositional element elicited by the momentary experience. Other terms for this momentary humility may be a "reality-check" or a "humbling moment," in which the person's dispositional humility is awakened, and the internal change occurs in the attitude of how one relates to others. Emotional readiness and mental maturity may be required to elicit dispositional humility by these reality-check moments. How productive criticism is given or how an environment provides the reality-check moment, like Chestnut being told that he would lose his professional position unless he changed his arrogant attitude toward nurses, should be further explored.

\section{Consequences of dispositional humility}

Dispositional humility is not likely to be exhibited saliently and with the awareness of the person. The common characteristic traits are people who like to learn from others, ${ }^{37}$ do not exhibit their status or accomplishment excessively, ${ }^{43}$ express gratitude to others and are able to apologize for mistakes. ${ }^{37}$ For professionals, these humble characteristics must be accompanied by competency and the fulfillment of professional responsibilities. Without the ability to perform professional roles, these humble attitudes may be perceived as incompetence and submissiveness, which do not benefit the professional collaborative relationship. The humble character must also be accompanied by a sense of morality and ethical behavior. Without being supported by ethical principles, humble attitudes may become IMBs (ingratiation or supplication) used to manipulate others for selfish reasons. The HEXACO inventory also contains the domain called "conscientiousness," which reflects the level of ethical strength. ${ }^{40}$ This domain must also be high along with the other $\mathrm{HH}$ domains for professionals with dispositional humility.

Competent individuals know their self-worth. Professionals accompanied by a record of accomplishment working in a complex and stressful environment, as in the example of David Chestnut, may express so much selfconfidence and overbearing pride that their capacity for dispositional humility is hidden. It may be the case that their capacity for dispositional humility has not been awakened because they have not been exposed to the "realitycheck" or "humble moment" of self-reflection. Not only dispositional characteristics but also emotional readiness and mental maturity may also play a role in character development. Chestnut found that being the department chair made him more unkind, demanding and impatient. He found that interpersonal relationships became more mechanical and respect was more of an entitlement rather than genuinely earned. Chestnut believes strongly that professional training is not finished at the end of formal education. 
Professionalism is not something we learn once, and no physician is perfectly professional at all times, in all circumstances. Professionalism is both a commitment and a skill - a competency - that we practice over a lifetime. (p. 780) ${ }^{37}$

Being self-aware, not overestimating one's own ability, being committed to learning and working toward otheroriented goals are the consequences as well as characteristics of dispositional humility.

As mentioned earlier, dispositional humility makes an individual aware of the good intentions of critics, causing less retaliatory behaviors. ${ }^{18}$ Professional success as well as financial entitlement due to the amount of education and training may cause clinicians to forget the sense of humility. Furthermore, if you cannot be fully present in the moment of communication with other professionals, and you handle such moments in a rushed manner, it may give the impression of arrogance and self-absorption, which is detrimental to developing trusting relationships. As a consequence of humility, a person is able to adopt the value of inclusiveness, ${ }^{28}$ providing an environment that facilitates the reporting of medical errors, transparency, fairness and equality, ${ }^{29}$ generosity to others, ${ }^{38}$ improved quality of relationships, ${ }^{44}$ and a reduction of dyadic stress. ${ }^{35}$

\section{Definition of dispositional humility}

Dispositional humility is a socially desirable trait and converged to a concept that includes: humble, modest, tolerant, down-to-earth, respectful, and open minded. ${ }^{45}$ The concept also has separation (divergent validity) to concepts like arrogant, egotistical, high-and-mighty, closed-minded, conceited ${ }^{45}$ and entitled. ${ }^{37}$ Dispositional humility is a character trait of lifelong learning to improve the self, to improve relationships with others, to be aware of the limitations of self, to appreciate and accept others and their values, and to be generous.

Dispositional humility of team leaders can create an environment that facilitates character development and the growth of the team members' dispositional humility. An example of such facilitative environments that can develop the team members' character are fairness and equality, transparency, dedication, non-punitive consequences for reporting errors and near misses, and a safe and encouraging environment for performing work. ${ }^{29}$ Hofmann (2015) described these requirements as "the organization's moral fabric as reflected by its values statement and code of conduct". (p. 28) ${ }^{29}$ Professional training should not only provide knowledge and behavioral skills but also focus on nourishing the "soul" of professionals.

\section{Results}

A concept map diagram of the qualitative analyses was created by incorporating key elements of the concept in Figure 2 .

A theoretically derived concept map can be used to test each component of the identified factors for future studies such as: 1) is "dispositional humility" a modifiable character trait, 2) what environmental factors are desirable, 3) can predisposing factors be identified that may cause professionals to lose their sense of humility, and 4) how can the "reality check" or "humbling moment" be provided? A sequel study testing whether or not clinicians identify humility as an important factor in interprofessional collaboration has been completed and the resulting manuscript is under review.

\section{Discussion}

Due to the complex nature of the US healthcare system, interprofessional collaboration among healthcare providers may involve cooperation between professions that may have developed with different social, political and economic interests, and also with different perspectives and philosophies; this is represented by different clinical credentials, types of training, schools and disciplines. For instance, the school of medicine and the school of nursing train clinical professionals with distinct healthcare philosophies and roles in the healthcare system. During the course of professional training, students invest considerable personal resources for the success of their profession. It is not surprising that an individual may form an affinity for his/her own professional members, which can unfortunately develop into "in-group favoritism" that creates barriers to collaboration with different professionals for a common purpose, for example in serving the needs of patients. Gratitude along with dispositional humility is meaningful in this regard because it is "appreciation of the value of all things, as well as the many different ways that people and things can contribute to our world". ${ }^{43}$ Dispositional humility has attributes that promote collaboration across professions with different social, political and economic interests, and also different philosophies and perspectives.

The commitment to lifelong learning and care for the "soul" of clinicians should be a part of training in professionalism. ${ }^{37}$ During the teaching of students or the mentoring of younger faculty members, the seeds of dispositional humility can grow in a nurturing environment. At times, providing the "moment of humility" or "reality-check" may benefit those successful professionals who may have neglected their "soul". Duffy (2009) wrote as he reflected on his medical education 


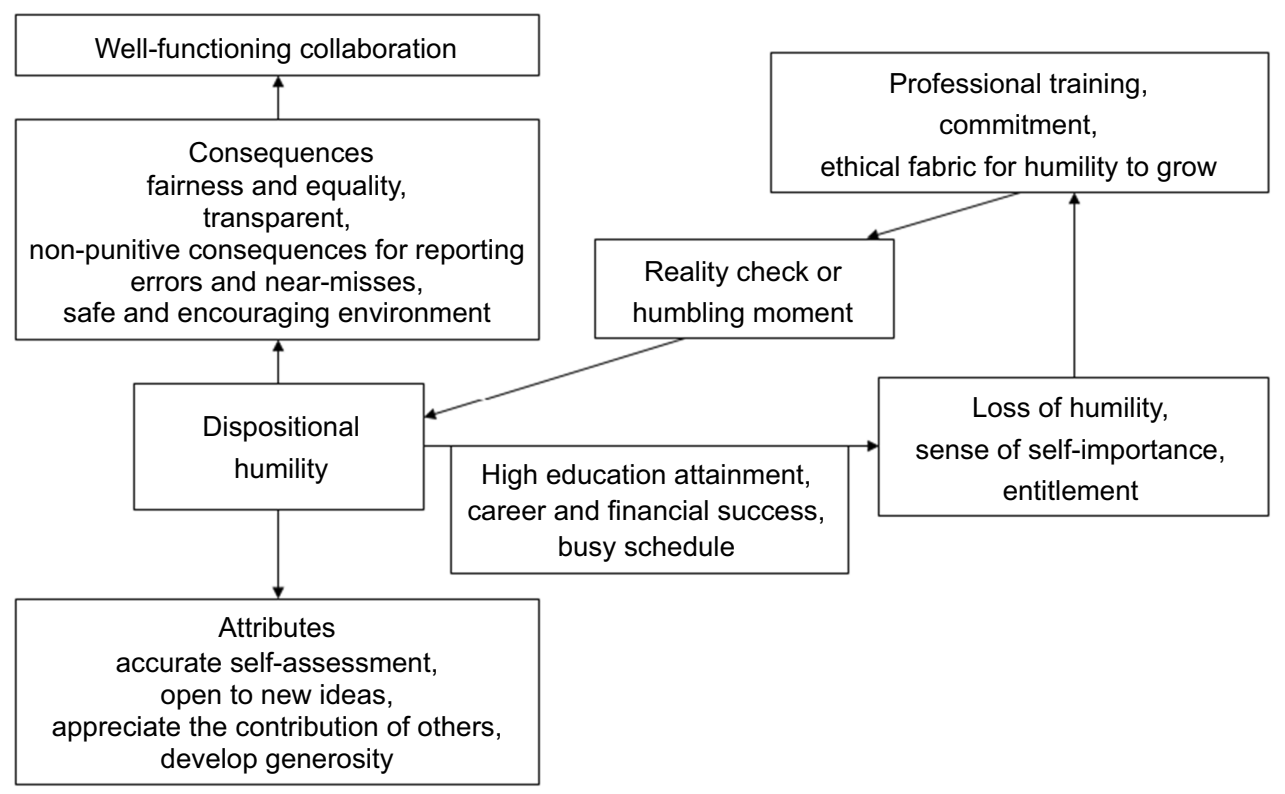

Figure 2 Concept map of dispositional humility. Dispositional humility allows clinicians to have an accurate self-assessment, be open to new ideas, appreciate the contribution of others, and develop generosity. Dispositional humility in leaders can facilitate character development of team members and create an environment characterized by fairness and equality, transparency, non-punitive consequences for reporting errors and near-misses, and a safe and encouraging environment for performing work. However, dispositional humility must be nurtured and developed through professional training because high educational attainment, career and financial success, and busy schedules may lead to a sense of self-importance and entitlement that can promote separation of team members into hierarchies based on professional disciplines and specialties.

Note: This is not structural equation modeling, and the pathways were not statistically analyzed.

and professional success, "I had lost any humility and gratitude I might have had, and replaced these attitudes with self-righteous pride, entitlement, and disregard for the feelings or welfare of others." (p. 24) ${ }^{46}$ The interprofessional collaborative model proposed by Mulvale et al (2016) uses individual healthcare professionals as the foundation for making adjustments in different types of interprofessional collaborations, and the ability of the individual to make adjustments is mediated by team attitudes, group processing, team structure, policy-level restrictions and patient characteristics ${ }^{50}$ that ultimately lead to high-quality and cost-effective healthcare. However, this model does not address the dispositional factors that each healthcare professional inevitably brings to the workplace.

\section{Limitations}

This concept map did not clarify whether "dispositional humility" is innate and unmodifiable or whether it is a modifiable and learnable character trait through professional training. Testing this hypothesis is a high priority for future studies. The proposed concept map is a small step toward advancing the idea of facilitating interprofessional relationship. The limitations of the study are also discussed in the qualitative rigor section and addressed by: credibility, dependability, confirmability, and transferability, because the synthesis of this concept map was qualitative. ${ }^{51}$ Credibility of the source documents and the Walker and Avant method of concept analysis were appropriate because the search was systematic and Walker and Avant's method is well established; however, the interpreted data from the searched articles could be improved if the synthesis had been conducted by more than two researchers. For example, the PRISMA flow diagram process was performed by MS only. Dependability refers to the reliability, consistency, or stability of data that were pulled from searched articles. Iteration procedures that improve reliability were lacking. Confirmability or objectivity of the data is weak because the map was inductively derived. A more rigorous quantitative method would utilize factor analysis. The transferability or external validity is considered good because dispositional humility was defined in the context of professional relations. While 95 articles for synthesis were appropriate, the 65 articles that failed due to inability to locate the full text articles might have resulted in changes to the final concept map. 


\section{Future research}

Dispositional humility cannot be safely expressed in an environment that lacks mutual respect. In other words, dispositional humility is a fertilizing factor for developing meaningful and cooperative relationships; however, prerequisite traits may be necessary and are described in The Power of Humility by Hofmann and Yates (2015). ${ }^{29}$ Dispositional humility shines in a healthy organizational culture, but may be fragile or difficult to maintain when the professional work environment does not emphasize or value it, and the level of empathy expressed and perceived by individuals is very much dependent on the context and social environment. ${ }^{52}$ As a result, humble professionals may be exploited and may leave an organization before burning out. Humble individuals may give others the benefit of the doubt for maltreatment or perceived inequality, but a recurrent pattern of workplace stressors cannot become the norm of the work culture and environment. Honesty-humility is a psychometrically defined facet of personality that is beneficial for developing cooperative and functional professional relationships. A second phase of this research utilized a mixed methods analysis of personality characteristics of clinicians and the analysis of interview transcripts regarding interprofessional collaboration without letting the participants know that dispositional humility was the object of study.

\section{Data sharing statement}

The literature search information was described.

\section{Abbreviations list}

HEXACO, Designating six domains of personality as Honesty-Humility, Emotionality, eXtraversion, Agreeableness, Conscientiousness, and Openness to experience; EMBASE, Excerpta Medica dataBASE, a biomedical and pharmacological database; CINAHL, Cumulative Index to Nursing and Allied Health Literature, an index of English-language and selected other-language journal articles about nursing, allied health, biomedicine and healthcare.

\section{Acknowledgments}

Linda Tally (Librarian) for literature search, Yoriko Kozuki, Ph.D for the guidance of overall project. Selffunded.

\section{Author contributions}

All authors contributed to data analysis, drafting or revising the article, gave final approval of the version to be published, and agree to be accountable for all aspects of the work.

\section{Disclosure}

The authors report no conflicts of interest in this work.

\section{References}

1. Paul R, Elder L. Critical Thinking: Tools for Taking Charge of Your Professional and Personal Life. (NJ): Pearson Education, Inc. FT Press; 2002.

2. Harper D. Online etymology dictionary. 2001. Available from: https://www.etymonline.com/. Accessed October 29, 2017.

3. Silverman A. Plato's republic as a vocation. In: Anagnostopoulos G, FDJ M, editors. Reason and Analysis in Ancient Greek Philosophy. New York: Springer; 2013;125.

4. Smith A. An Inquiry into the Nature and Causes of the Wealth of Nations. New York: MetaLibri Digital Edition; 1776 (2007).

5. Parsons T. The professions and social structure. Soc Forces. 1939;17 (4):457-467. doi: $10.2307 / 2570695$

6. Dowd S, Davidhizar R, Giger JN. The mystery of altruism and transcultural nursing. Health Care Manag (Frederick). 2007;26 (1):64-67.

7. Passi M, Doug M, Peile E, Thistlethwaite J, Johnson N. Developing medical professionalism in future doctors: a systematic review. Int $J$ Med Educ. 2010;1:16-29. doi:10.5116/ijme.4bda.ca2a

8. Walker L, Avant K. Strategies for Theory Construction in Nursing. 3rd ed. Norwalk (CT): Appleton \& Lange; 1995.

9. Lindhiem O, Bennett CB, Trentacosta CJ, McLear C. Client preferences affect treatment satisfaction, completion, and clinical outcome: a meta-analysis. Clin Psychol Rev. 2014;34(6):506-517. doi:10.1016/ j.cpr.2014.06.002

10. Greenwald AG, McGhee DE, Schwartz JL. Measuring individual differences in implicit cognition: the implicit association test. $J$ Pers Soc Psychol. 1998;74(6):1464-1480.

11. Banja J. Humility and Leadership. Healthc Exec. 2015;30(1):50,5253.

12. Liu W, Mao J, Chen X. Leader humility and team innovation: investigating the substituting role of task interdependence and the mediating role of team voice climate. Front Psychol. 2017;8:1115. doi:10.3389/fpsyg.2017.01115

13. Chiu CC, Owens BP, Tesluk PE. Initiating and utilizing shared leadership in teams: the role of leader humility, team proactive personality, and team performance capability. $J$ Appl Psychol. 2016;101(12):1705-1720. doi:10.1037/ap10000159

14. Hu J, Erdogan B, Jiang K, Bauer TN, Liu S. Leader humility and team creativity: the role of team information sharing, psychological safety, and power distance. J Appl Psychol. 2017.103(3):313-323.

15. Braun S. Leader narcissism and outcomes in organizations: a review at multiple levels of analysis and implications for future research. Front Psychol. 2017;8:773. doi:10.3389/fpsyg.2017.00773

16. Owens BP, Wallace AS, Waldman DA. Leader narcissism and follower outcomes: the counterbalancing effect of leader humility. $J$ Appl Psychol. 2015;100(4):1203-1213. doi:10.1037/a0038698

17. Romanowska J, Larsson G, Theorell T. An art-based leadership intervention for enhancement of self-awareness, humility, and leader performance. J Pers Psychol. 2014;13(2):97-106. doi:10.1027/18665888/a000108 
18. Van Tongeren DR, Davis DE, Hook JN, Rowatt,W, Worthington EL, Jr. Religious differences in reporting and expressing humility. Psychology of Religion and Spirituality. 2018;10(2):174184.

19. Krause N. Religious involvement, humility, and self-rated health. Soc Indic Res. 2010;98(1):23-39. doi:10.1007/s11205-009-9514-x

20. Masuda N, Fu F. Evolutionary models of in-group favoritism. F1000Prime Rep. 2015;7:27. doi:10.12703/P

21. Stroebe K, Lodewijkx HF, Spears R. Do unto others as they do unto you: reciprocity and social identification as determinants of ingroup favoritism. Pers Soc Psychol Bull. 2005;31(6):831-845. doi:10.1177/ 0146167204271659

22. Lee M, Pagano M, Johnson B, Post S, Leibowitz G, Dudash M. From defiance to reliance: spiritual virtue as a pathway towards desistence, humility, and recovery among juvenile offenders. Spiritual Clin Pract. 2017;4(3):161-175. doi:10.1037/scp0000144

23. Juarez JA, Marvel K, Brezinski KL, Glazner C, Towbin MM, Lawton S. Bridging the gap: a curriculum to teach residents cultural humility. Fam Med. 2006;38(2):97-102.

24. Kutob RM, Bormanis J, Crago M, Harris JM Jr, Senf J, Shisslak CM. Cultural competence education for practicing physicians: lessons in cultural humility, nonjudgmental behaviors, and health beliefs elicitation. J Contin Educ Health Prof. 2013;33(3):164-173. doi:10.1002/ chp. 21181

25. Prasad SJ, Nair P, Gadhvi K, Barai I, Danish HS, Philip AB. Cultural humility: treating the patient, not the illness. Med Educ Online. 2016;21:30908. doi:10.3402/meo.v21.29332

26. Tervalon M, Murray-Garcia J. Cultural humility versus cultural competence: a critical distinction in defining physician training outcomes in multicultural education. $J$ Health Care Poor Underserved. 1998;9 (2):117-125.

27. Hook JN, Watkins CE. Cultural humility: the cornerstone of positive contact with culturally different individuals and groups? Am Psychol. 2015;70(7):661-662. doi:10.1037/a0038965

28. Alsharif NZ. Cultural humility and interprofessional education and practice: a winning combination. Am J Pharm Educ. 2012;76(7):120. doi:10.5688/ajpe76232

29. Hofmann PB, Yates GR. The power of humility. Trustee. 2015;68 (9):27-28.

30. Gruppen LD. Humility and respect: core values in medical education. Med Educ. 2014;48(1):53-58. doi:10.1111/medu.12269

31. McElroy S, Rice K, Davis D, et al. Intellectual humility: scale development and theoretical elaborations in the context of religious leadership. $J$ Psychol Theol. 2014;42(1):19-30. doi:10.1177/ 009164711404200103

32. Zhang H, Hook JN, Farrell JE, Mosher DK, Van Tongeren DR, Davis DE. The effect of religious diversity on religious belonging and meaning: The role of intellectual humility. Psychology of Religion and Spirituality. 2018;10(1):72-78.

33. Davis DE, Hook JN, Worthington EL Jr, et al. Relational humility: conceptualizing and measuring humility as a personality judgment. $J$ Pers Assess. 2011;93(3):225-234.

34. Freitas J, Martins M, Davis D. Contributions to the validation of the Humility Relational Scale. Open Sci J Psychol. 2014;1(1):1-9.

35. Ripley J, Garthe R, Perkins A, et al. Perceived partner humility predicts subjective stress during transition to parenthood. Couple Family Psychol. 2016;5(3):157-167. doi:10.1037/cfp0000063
36. Farrell J, Hook J, Ramos M, Davis D, van Tongeren D, Ruiz J. Humility and relationship outcomes in couple: the mediating role of commitment. Couple Family Psychol. 2015;4(1):14-26. doi:10.1037/ cfp0000033

37. Chestnut DH. On the Road to Professionalism. Anesthesiology. 2017;126(5):780-786. doi:10.1097/ALN.0000000000001545

38. Exline J, Humility: HP. A consistent and robust predictor of generosity. $J$ Posit Psychol. 2012;7(3):208-218. doi:10.1080/17439760.2012.671348

39. Lee K, Ashton MC The HEXACO personality inventory - revised. 2009. Available from: www.hexaco.org. Accessed June 24, 2019.

40. Ashton MC, Lee K, de Vries RE. The HEXACO Honesty-Humility, Agreeableness, and Emotionality factors: a review of research and theory. Pers Soc Psychol Rev. 2014;18(2):139-152.

41. Anglim J, Knowles E, Dunlop P, Marty A. HEXACO personality and Schwartz's personal values: a facet-level analysis. J Res Pers. 2017;68:23-31. doi:10.1016/j.jrp.2017.04.002

42. Pfattheicher S, Bohm R. Honesty-humility under threat: self-uncertainty destroys trust among the nice guys. J Pers Soc Psychol. 2018;114(1):179-194. doi:10.1037/pspp0000144

43. Tangney J. Humility: Theoretical perspectives, empirical findings and directions for future research. J Soc Clin Psychol. 2000;19(1):70-82. doi:10.1521/jscp.2000.19.1.70

44. Peters A, Rowatt W, Johnson M. Associations between dispositional humility and social relationship quality. Psychology. 2011;2(3):155161. doi: $10.4236 /$ psych.2011.23025

45. Landrum RE. Measuring dispositional humility: a first approximation. Psychol Rep. 2011;108(1):217-228. doi:10.2466/02.07.09. PR0.108.1.217-228

46. Duffy F. Medicine and care of the soul. Caution: becoming a doctor may be hazardous!.In Balancing Competing Goods in the Learning Environment. Ingrid Philibert, Editor. ACGME Bulletin. 2009. p. 23.

47. Bourdage JS, Wiltshire J, Lee K. Personality and workplace impression management: correlates and implications. J Appl Psychol. 2015;100(2):537-546. doi:10.1037/a0037942

48. Dunlop PD, Bourdage JS, de Vries RE, Hilbig BE, Zettler I, Ludeke SG. Openness to (reporting) experiences that one never had: overclaiming as an outcome of the knowledge accumulated through a proclivity for cognitive and aesthetic exploration. J Pers Soc Psychol. 2017;113(5):810-834. doi:10.1037/pspp0000110

49. Weidman AC, Cheng JT, Tracy JL. The psychological structure of humility. J Pers Soc Psychol. 2018;114(1):153-178. doi:10.1037/ pspp0000112

50. Mulvale G, Embrett M, Razavi SD. 'Gearing Up' to improve interprofessional collaboration in primary care: a systematic review and conceptual framework. BMC Fam Pract. 2016;17:83. doi:10.1186/ s12875-016-0492-1

51. Lincoln Y, Guba E. Naturalistic Inquiry. Newbury Park (CA): Sage Publications; 1985.

52. Kirman A, Teschl M. Selfish or selfless? The role of empathy in economics. Philos Trans $R$ Soc Lond B Biol Sci. 2010;365 (1538):303-317. doi:10.1098/rstb.2009.0192

53. Moher D, Liberati A, Tetzlaff J, Altman DG, Group P. Preferred reporting items for systematic reviews and meta-analyses: the PRISMA statement. PLoS Med. 2009;6(7):e1000097. doi:10.1371/ journal.pmed.1000097 


\section{Publish your work in this journal}

The Journal of Multidisciplinary Healthcare is an international, peerreviewed open-access journal that aims to represent and publish research in healthcare areas delivered by practitioners of different disciplines. This includes studies and reviews conducted by multidisciplinary teams as well as research which evaluates the results or conduct of such teams or healthcare processes in general. The journal covers a very wide range of areas and welcomes submissions from practitioners at all levels, from all over the world. The manuscript management system is completely online and includes a very quick and fair peer-review system. Visit http://www.dovepress.com/testimonials. php to read real quotes from published authors. 